\title{
Os dragões invadem a cidade: uma leitura da hospitalidade em Murilo Rubião
}

Filipe Amaral Rocha de Menezes

Mestrando no Programa de Pós-Graduação em Letras: Estudos Literários - UFMG

Resumo:

Por meio de uma análise crítica do conto "Os dragões" de Murilo Rubião, seu detalhamento e sua comparação com dois textos bíblicos, pretendese demonstrar como uma comunidade coesa tem dificuldade em aceitar o diferente em seu meio. Considerado um grave delito pela cultura judaica bíblica, a quebra da lei da hospitalidade, será analisada, neste ensaio, tendo por cruzamento os textos "Ló recebe em sua casa os dois anjos" (Gn 19:2-22) e "O levita e sua concubina" (Jz 19) e também a inserção do monstro ou do estranho no meio de uma comunidade homogênea.

Palavras-chave: Murilo Rubião; hospitalidade; monstros

\section{INTRODUÇÃO}

Fui irmão de dragões e companheiro de avestruzes.

Jó 30:29

A epígrafe acima, retirada do livro de Jó, amplia, de forma paradigmática, a compreensão do estranho e do estrangeiro no conto "Os dragões", de Murilo Rubião. A sentença proferida em um dos últimos momentos de lamentação e de miséria em que o personagem bíblico teria caído traz a luz essas inusitadas referências zoológicas, os dragões e os avestruzes.

O relato bíblico faz referência à justiça e à retidão de Jó, consideradas e dignas de elogios do próprio Deus, e o questionamento por parte de Satanás, ${ }^{1}$ que recebe a permissão para tentar Jó, num teste de sua fé, que sofre, num primeiro momento, grandes perdas materiais e, também, a morte de seus filhos. Mesmo assim, ele mantém sua fé. No segundo momento, Jó é afligido por várias doenças que o tornam, ele mesmo, uma figura repulsiva. 0 texto bíblico trata assim, par e passo, com a narrativa dos flagelos sofridos por um justo, das suas reflexões e lamentos, além de seus debates filosóficos com três amigos sobre a vida, as leis de Deus, o significado da fé.

${ }^{1}$ BÍBLIA SAGRADA. Jó 1-2, p. 719-721. 
A referência a dragões, no entanto, é estranha a esse universo hebraico. O vocábulo, traduzido por dragões, é תּ̊ tannîyn ou tannîym, que pode ser entendido por crocodilo, serpente ou um nome genérico de grandes animais marinos. ${ }^{2} \mathrm{Na}$ tradução da Septuaginta, o termo aparece como sereia, no sentido de mostro marinho. Já o texto da Vulgata passa a utilizar draconum, dragão, no sentido de monstro ou crocodilo enorme. Na versão de João Ferreira de Almeida, revista e corrigida, do final do século 19, ainda encontramos o vocábulo dragão. Nas versões em português contemporâneo, adota-se, muitas vezes, o vocábulo chacal.

Os chacais, parentes dos lobos e das raposas, são conhecidos por sua ferocidade, agrupam-se em matilhas e são exímios ladrões de galinheiros e hortas, destruindo tudo o que não conseguem comer. Já, os avestruzes, do hebraico יענה, ya 'anah, animais marcados por sua suposta crueldade no trato com seus filhotes e nada do que se poderia chamar de instinto materno. ${ }^{3}$

Ao associar-se a tais animais, Jó reforça os seus sentimentos de exílio e de desterro, tamanho era o seu sofrimento e sua miséria. Ser companheiro ou irmão é compartilhar o jugo, isto é, ser tão solitário, exótico ou diferente como eles. Caracteriza-se, por isso, como um estrangeiro que, desprezado e só, depende da misericórdia alheia. Sendo assim, Jó prefiguraria o sofrimento de um estrangeiro que, perseguido, parece depender somente de Deus.

Monstros marinhos, chacais, avestruzes e dragões, mesmo a partir de tantas possibilidades significativas que acompanham as traduções, compõem um bestiário ligado a Jó, seja na cultura judaica ou cristã. Esse bestiário também aponta, no conto de Rubião, para aqueles que são chamados de estranhos, os desconhecidos e que, mesmo estando por perto, não são aceitos. Sua presença causa repulsa e, na maioria das vezes, violência, simbólica ou real. Sendo assim, a atualização de tannîyn para dragões, no contexto literário de Rubião, resignifica o seu estranhamento.

A simbologia do dragão está presente nas mais antigas mitologias. Entre os hindus, os chineses e japoneses, até mesmo entre as populações americanas pré-colombianas como a asteca, há representações muito aproximadas entre si. Simboliza o bem, o mal, a energia criadora ou destruidora. Para a doutrina hindu, o dragão produz o soma, a bebida da imortalidade. Para Confúcio, ele é personificação de Lao-tse, e similarmente leva a mesma imortalidade. Na mitologia chinesa, tem várias representações. São as montarias dos imortais. Por sua potência criadora e ordenadora simbolizam o Imperador. Acredita-se que o dragão carrega uma pérola ao pescoço - a pérola é a indiscutível palavra do chefe. A associação dragão-raio-chuva-fecundidade faz parte da cultura chinesa e o investe de uma simbolização cósmica, a vida rítmica. Borges cita Confúcio em $O$ livro dos seres imaginários falando sobre o seu imaginário do: "os pássaros voam, os peixes nadam e os animais correm. O que corre pode ser detido por uma armadilha, o que nada por uma rede e o que voa por uma flecha. Mas aí está o dragão; não sei como cavalga no vento nem como chega ao céu". ${ }^{4}$

Já na cultura ocidental, de influência judaico-cristã, ele representa o mal, sendo associação à serpente. Por toda a Bíblia são feitas citações de tal ser fantástico. É frequentemente associado ao monstro Leviatã. Em alguns textos bíblicos, como citado acima, nas traduções atuais, os monstros marinhos ou crocodilos, os "dragões" judeus, são ligados à figura do Faraó egípcio, este também símbolo do mal e do opressor. Na hagiologia cristã, ele sempre aparece destruído, derrotado como nas imagens de São Jorge e São Miguel. No livro de Apocalipse, Satanás é chamado de "o grande dragão, a antiga serpente" ${ }^{5}$ E conforme está

\footnotetext{
${ }^{2}$ TANNÎYN. In: BEREZIN. Dicionário Hebraico-Português, p. 672.

${ }^{3}$ BÍBLIA SAGRADA. Jó 39:13-18, p. 767-768.

${ }^{4}$ BORGES. O livro dos seres imaginário, p. 79-80.

${ }^{5}$ BÍBLIA SAGRADA. Ap 12:9, p. 1.772.
} 
escrito em Gêneses, "Este te ferirá a cabeça, e tu Ihe ferirás o calcanhar", ${ }^{6}$ referindo-se à luta entre o bem (o Messias) e o mal (Satanás).

OS DRAGÕES E A CONDIÇÃO HUMANA DA LIMITAÇÃO

(...) chaque homme porte la forme entière de I'humaine condition.

Montaigne

Os dragões são os personagens principais desse conto de Murilo Rubião. Como estrangeiros peregrinando em terra alheia, assim como Jó, necessitam da compreensão e da misericórdia da comunidade ${ }^{7}$ para a qual eles migram e tentam se ajustar. 0 texto demonstra como essa comunidade, com suas limitações, procura assimilar a ideia de seres tão singulares, que com suas diferenças, penetram em seu seio.

Em L'humaine condition, Montaigne afirma que cada ser humano tem dentro de si a condição humana de forma completa, quer seja ilustre, quer seja comum - todo ser humano é cheio dessa condição. No relato bíblico da criação, no diálogo de Deus com Adão, logo após o Pecado Original, Deus lembra a Adão: "és pó, e ao pó tornarás" (Gn 3:19). Lembrou-o, assim, o Criador, da condição limitada do homem, de que um dia iria morrer e voltar à sua matéria original. Esse texto está intimamente ligado ao que Montaigne disse: "A condição humana é a sua limitação, o homem é fraco e esse estado deve ser aceito."

A limitação do homem e como este lida com sua condição é tema da literatura universal. Interessa, portanto, ao homem observar e avaliar como cada comunidade entende e trabalha os seus limites morais e culturais. Em "Os dragões" temos, assim, uma metáfora desses limites humanos, postos em cena, a partir da simulação de criação de uma determinada comunidade que passa por uma grande dificuldade: compreender os estrangeiros recémchegados.

Como pequenos capítulos de um texto maior, uma espécie de romance da alteridade condensado em forma de conto, "Os dragões" é divido em cinco partes: $1^{a}$ ) o choque inicial da comunidade e sua tentativa de classificar os estrangeiros que, de repente, invadem a cidade; $2^{a}$ ) o início de uma tentativa de absorção desses elementos estrangeiros à comunidade; $3^{a}$ ) sobre o dragão Odorico e o seu fim; $4^{a}$ ) sobre o dragão João e sua fuga; e, finalmente, $5^{a}$ ) a continuidade da incomunicabilidade com os estranhos/estrangeiros, mas sua contínua atração por eles.

Os dragões não são exaustivamente descritos. O texto enxuto de Rubião oferece, ao contrário, uma concentração de sentidos, ao preferir a forma contida do conto. Existe apenas, é possível dizer, um maior detalhamento sobre as qualidades do narrador-personagem, o professor da cidade, quanto aos defeitos dos dragões. Eles se embebedam, não cumprem as leis da educação regulada pela comunidade, estão, continuamente, entre uma aventura e outra, contrariando as normas estabelecidas por aquela comunidade.

Como era de se esperar, as crianças, no entanto, seriam as únicas a entender que aqueles seres estranhos, os novos companheiros, "eram simples dragões", mas elas não foram ouvidas. As crianças nunca são ouvidas. O professor narra os fatos, pontuando, com sua análise minuciosa, seus sentimentos. O choque inicial sofrido pela comunidade local seria por ele avaliado como um "atraso" dos costumes. Os dragões, todavia, não foram compreendidos

\footnotetext{
${ }^{6}$ BÍBLIA SAGRADA. Gn 3:15b, p. 5.

7 "Pois o SENHOR, vosso Deus, é o Deus dos deuses e o Senhor dos senhores, o Deus grande, poderoso e temível, que não faz acepção de pessoas, nem aceita suborno; que faz justiça ao órfão e à viúva e ama o estrangeiro, dando-lhe pão e vestes." BÍBLIA SAGRADA. Dt 10:17-18, p. 267.
} 
nem quando chegaram, nem depois, apesar de sua permanência. A tentativa de assimilação através da classificação por parte da população, em geral, do padre, de alguns personagens esparsos, tentam de alguma forma enquadrá-los como "coisa asiática, de importação europeia", "monstros antediluvianos", "mulas-sem-cabeça, lobisomens", ou apenas dragões como fizeram as crianças. Sem um consenso, a comunidade procura, por fim, dar utilidade, tornar útil o que não pode ser entendido.

De fato, na sua condição de limitação, o homem intenta classificar, nomear e usar. Pensa, talvez, dessa forma, compreender e dar forma ao diferente e ao estranho. O narrador destaca, nesse contexto, a atitude das crianças que simplesmente os aceitam e, não tendo a necessidade de classificar e nomear para absorvê-los, sem o olhar adestrado que a civilização impõe, pode de alguma maneira, aceitá-los em sua barbárie.

A tentativa de absorção ou assimilação dos dragões estrangeiros pela comunidade, ao tentar batizá-los, por exemplo, fracassa. Eles continuam sendo rejeitados de modo brando, aceitos apenas como objeto exótico e não como iguais. Os dragões sobreviventes, afiança o narrador, teriam sido corrompidos por conta de sua não aceitação. Entregues à bebida, ao jogo, e aos vícios, muito comuns em humanos, continuam sendo, para esses mesmos humanos, párias.

De todo, o estrangeiro desfruta de algumas regalias, não por ter sido aceito, mas por ser diferente. Os dragões, assim, descritos como muito carismáticos, atraíam até o amor de mulheres, eram populares entre jovens, e um deles, João, "alimentava ainda a pretensão de se eleger prefeito municipal", arremata o narrador ironicamente. Entretanto, a trama concluise e, tanto João quanto Odorico são expurgados da cidade: Odorico é morto pelo marido de sua amante e João foge com o circo.

O conto finaliza com uma reiterada incompreensão do narrador. Por que, afinal, os dragões não teriam se adaptado? Cheio de culpa pela não absorção dos estrangeiros pela comunidade, continua a convidar outros dragões a permanecer entre eles. Outros dragões passam por perto dessa cidade imaginária, contudo, não aceitam o convite insistente do professor e de seus alunos para que fiquem.

\section{OS DRAGÕES E A REPRESENTAÇÃO DO MONSTRO}

Os personagens monstruosos, João e Odorico, são representações monstruosas cheias de significado, mesmo eles sendo tão humanos. Os monstros são esses seres híbridos, meio humanos. A criação de personagens com essas características apresenta várias motivações e sentidos. No texto "A cultura dos monstros: sete teses", Jeffrey Cohen propões sete postulados que tentam explicar como os monstros funcionam na literatura e apresentam algumas respostas sobre sua criação. $O$ uso desse artifício criativo não é desprezado por Rubião, pois os dragões se encaixam perfeitamente nas teses apresentadas.

A primeira delas, afirma ser o monstro uma construção cultural, a revelação de uma época, de um sentimento e de um lugar. Eles são marcados por todo um sistema a volta do seu criador: a cultura tanto local quanto de uma época, o estilo, o interesse do autor, etc. João e Odorico poderiam ser classificados como típicos brasileiros, são personagens próprios da cultura brasileira, o estereótipo do homem, do boêmio: são vaidosos, mas beberrões e mulherengos, acabam se envolvendo com mulheres complicadas e paixões explosivas - um deles se amasia com uma mulher casada e o outro foge com a trapezista do pequeno circo que visitara a vila. São afeitos a noitadas e vivem de mal humor, "proveniente das noites mal dormidas e ressacas alcoólicas". Essas características representam os desejos de liberdade e libertinagem de toda uma geração, e esse comportamento marginal é extremamente valorizado em toda a literatura. 
O uso da figura do dragão para caracterizar esses personagens diaspóricos corresponde ao segundo postulado proposto. Segundo Cohen o monstro sempre escapa no final, ele desaparece, mas reaparece usando novas roupagens. Seria impossível utilizar-se da figura do dragão tal qual era vista pela mitologia ou pela cultura em geral: um ser poderoso, austero, símbolo de impérios e imperadores, terrível. Os dragões do texto são muito humanos, muito mortais, nada tem a ver com seus antepassados. No início da narrativa, apesar do pavor que causavam na população da vila, o texto diz que eles têm aparência dócil e meiga, mas mesmo assim são classificados como monstros comparáveis a lobisomens ou mulas-sem-cabeça.

Eles são inclassificáveis. Há uma enorme tentativa de seu enquadramento pelos outros personagens, mas sem êxito. $O$ terceiro postulado apresenta o monstro como uma verdadeira "recusa a fazer parte da 'ordem classificatória das coisas' (...) eles são híbridos que perturbam". ${ }^{8}$ Mas certamente, mesmo não sendo possível se dizer sua classe, são o disfarce do inimigo, do indesejado. Na quarta tese, o monstro é apresentado como uma maquiagem feita sobre o inimigo ou indesejado, para se reforçar o ódio e o desprezo, e até mesmo justificar tais sentimentos ou o seu extermínio. A alteridade dos dragões, talvez uma alteridade racial ou entre espécies, é reforçada por sua imagem monstruosa e comportamento limiar ou marginal - justifica-se o seu tratamento reificante e ou como coisa exótica: "Serviu de pretexto uma sugestão do aproveitamento dos dragões na tração de veículos. (...) Nenhuma festa alcança o êxito sem a sua presença. Mesmo o padre não dispensava o seu comparecimento às barraquinhas do padroeiro da cidade."

Essa situação de atração pelo exótico e pelo temor, presente no comportamento da população da cidade imaginária de Rubião, é a sexta tese. Cohen explica essa atração pelo fato de os monstros estarem ligados a práticas proibidas, ocultas. Daí, a atração que exercem. Seria como um movimento de repulsão e atração. Assim como os dragões são discriminados, isolados em uma casa velha, reificados, abandonados, ao final eles acabam também por serem atrações, alvos de paixões e ciúmes.

Por fim, as teses quinta e sétima falam sobre a situação limítrofe do monstro. Ele é o vigia dos limites da cultura. Eles nos alertam para o limiar. Eles agem como os dragões chineses que protegem um tesouro, e o seu tesouro na verdade são as limitações culturais, quer sejam geográficas, intelectuais, sexuais, raciais, etc. Ao ultrapassar essas barreiras corremos o risco da punição. Os dragões de Rubião nos alertam para os riscos da incomunicabilidade e da corrupção causada por nós mesmos. O texto alerta, com uma frase quase imperceptível no início, sobre a moral dos estrangeiros corrompida pela sociedade, fruto dos desentendimentos e da precária comunicação. Por fim, não somos transformados em dragões por causa desse erro, mas nos tornamos seus assassinos e perdemos a capacidade de comunicarmos com eles, que "encaminham-se para outros lugares, indiferentes aos nossos apelos".

\section{A TRADIÇÃO DA HOSPITALIDADE}

Segundo os textos bíblicos, os judeus foram exilados, além de escravizados, por cerca de quatrocentos anos no Egito. Deus, por ouvir suas súplicas, teria enviado Moisés para tirá-los dessa condição e guiá-los à terra prometida de Canaã. Desse episódio originou-se a Lei e os Dez Mandamentos foram entregues a Moisés.

Um dos ensinamentos aprendidos pelos hebreus no deserto é o do tratamento que se deve dar aos estrangeiros. O primeiro exemplo dessa hospitalidade foi dado por Abraão. ${ }^{9}$ Segundo o Gn. 18, três homens apareceram a Abraão, enquanto ele descansava à porta de

${ }^{8}$ COHEN. A cultura dos monstros: sete teses, p. 23-60.

${ }^{9}$ BÍBLIA SAGRADA. Gn 18:1-22, p. 21-22. 
sua tenda na hora mais quente do dia. De acordo com Russell Shedd, o terceiro era o próprio Deus revestido em forma humana, numa espécie de teofania. Abrão correu para encontrá-los e suplicou que se hospedassem com ele. Trouxe água para lavar seus pés e mandou fazer um grande banquete com o que havia de melhor: pães assados no borralho, com a melhor farinha, um bom novilho assado, coalhada e leite. Após a refeição, passeou com os hospedes e nesse momento descobriu de quem se tratavam. Esse texto, assim como as passagens referentes ao período de cativeiro do povo hebreu no Egito, é usado, com frequência, ao se regular o tratamento que deve ser conferido a estrangeiros.

$\mathrm{Na}$ concepção de uma cultura muito anterior a qualquer ideia de turismo, as viagens, na antiguidade, eram apenas para negócios ou para fugas. Aos viajantes só era possível se oferecer hospedagem em estalagens que não passavam de meros rústicos abrigos ou, ainda, nas casas dos moradores locais. Os estrangeiros poderiam ser comerciantes, fugitivos ou peregrinos de terras distantes. Além das dificuldades enfrentadas por qualquer estrangeiro em uma cultura que não a própria, na maioria dos lugares, eles não possuíam certos direitos como participar das celebrações religiosas ou mesmo trabalhar. Entre os hebreus, porém, eram protegidos por leis num sentido de igualdade. Em Levítico se afirma: "Como o natural, será entre vós o estrangeiro que peregrina convosco; amá-lo-eis como a vós mesmos, pois estrangeiros fostes na terra do Egito. Eu sou o SENHOR, vosso Deus." ${ }^{10}$ Além de Levítico, outros livros como Números e Deuteronômio contêm essas regras.

A lembrança do passado de cativeiro e de exílio é usada para reforçar, assim, o tratamento que deve ser dado aos estrangeiros. Tendo os mesmos direitos que viúvas e órfãos, os estrangeiros eram, portanto, dependentes da misericórdia alheia. Podiam frequentar as segas, não trabalhando assalariadamente, mas colhendo o que os ceifeiros deixavam cair, ${ }^{11}$ tanto nos campos de trigo, quanto nos olivais e nas vinhas. Havia algumas celebrações festivas que podiam participar como Pentecostes ${ }^{12}$ e Tabernáculos, ${ }^{13}$ e era até mesmo possível uma conversão à religião dos hebreus. ${ }^{14} \mathrm{O}$ estrangeiro era amado por Deus e devia ser aceito e bem tratado pela comunidade. ${ }^{15}$

Entretanto, apesar de toda a recomendação aos hebreus e da tradição da hospitalidade entre outros povos orientais, há, na narrativa bíblica, descritos pelos textos de Gn 19:1-22 e Jz 19, a quebra da lei da hospitalidade.

No primeiro texto, em Gênesis, os mesmos anjos que já haviam sido hospedados por Abraão vão ao encontro de Ló, seu sobrinho, reconhecidamente o único justo nas cidades de Sodoma e Gomorra. Os anjos haviam compartilhado com Abraão a intenção de Deus destruir estas cidades por conta de suas abominações. ${ }^{16}$ Ao chegar à cidade de Sodoma, Ló os encontra e os convida a se hospedar em sua residência. Este também era estrangeiro e morava a certo tempo na cidade. Ló era um homem justo e faz exatamente como Abraão oferecendo-Ihes um banquete. Pouco tempo depois, a casa é cercada pelos homens da cidade que ordenam que os visitantes sejam expostos para, segundo várias interpretações, serem abusados sexualmente. Entretanto, para cumprir as regras da hospitalidade, Ló suplica a eles que não façam tal mal e chega até mesmo a oferecer suas duas filhas no lugar dos hóspedes.

Confirmam-se, assim, de acordo com a tradição interpretativa desse episódio, os inúmeros pecados praticados pelos habitantes dessas cidades. Sendo assim, os homens que

\footnotetext{
${ }^{10}$ BÍBLIA SAGRADA. Lv 19:34, p. 169.

${ }^{11}$ BÍBLIA SAGRADA. Dt 24:19, p. 286.

${ }^{12}$ BÍBLIA SAGRADA. Dt 26:11, p. 288.

${ }^{13}$ BÍBLIA SAGRADA. Dt 26:14, p. 288.

${ }^{14}$ BÍBLIA SAGRADA. Is 56:3-7, p. 1.044.

${ }^{15}$ BÍBLIA SAGRADA. Ex 23:9, p. 107; Lv 19:10,34, p. 168-169; Dt 10:19, p. 267; Dt 24:14, p. 286; Dt

26:12, p. 288; Dt 27: 19, p. 289; Dt 28:43, p. 289; Jó 31:32, p. 756; SI 146:9, p. 908

${ }^{16}$ BÍBLIA SAGRADA. Gn 18:16-21, p. 22.
} 
cercaram a casa de Ló violariam o sagrado rito da hospitalidade com uma das mais infames manifestações de seus pecados. A pederastia, que era comum entre os povos cananeus, ${ }^{17}$ aos quais eles pertenciam, era praticada como parte dos cultos pagãos - por isso, é altamente proibida e rechaçada nas leis judaicas, para não haver associação entre os escolhidos de Deus e os pagãos. ${ }^{18}$

Já no texto de Juízes, a situação é um pouco diferente. Num contexto muito anterior ao período histórico dos reinados de Davi e Salomão, houve uma época em que juízes governavam e cuidavam das querelas entre o povo hebreu. Nesse tempo, havia um levita que em uma viagem tomou para si uma concubina, que foge em seguida. O levita foi ao seu encalço. Na volta para sua casa, o levita, sua concubina e um ajudante procuraram refúgio à noite em uma cidade pertencente aos benjamitas, descendentes também de Jacó, na cidade de Gibeá. Antes de decidir-se por essa cidade, tomaram o cuidado de não pousar em Jebus, futura Jerusalém - na época, uma cidade gentia, habitada pelos jebuseus, antigo povo cananeu.

Da mesma forma, como no texto de Gênesis, quiseram pernoitar na praça central da cidade, e um homem idoso, vendo-os, convidou-os a se hospedarem com ele. Também estes foram cercados pelos homens da cidade que clamavam por abusar dos viajantes. $O$ idoso tentou convencê-los do contrário, mas eles resistiam e, por final, entregaram a concubina do levita à turba, que a violentaram até a morte.

A grave diferença encontrada nesse segundo texto é que os habitantes da cidade que queriam abusar dos visitantes faziam parte do povo hebreu. Gibeá pertencia a tribo de Benjamin. O grave delito cometido por eles, da quebra da hospitalidade e da bruta morte da concubina, resulta em uma guerra fratricida, quase um genocídio. Esse texto, tal qual o de Gênesis, pode se configurar como mitos para se justificar a destruição de Sodoma e Gomorra ou poderia ser uma lenda criada posteriormente para se justificar essa guerra entre as tribos do povo de Israel. Utilizam-se, a partir dessa constatação, os maus-tratos ao estrangeiro e a dificuldade em lidar com eles no seu meio, como uma quebra da lei da hospitalidade. Justificam-se, assim, os males ocorridos: a destruição de suas cidades e a quase eliminação de uma das doze tribos de Israel.

\section{CONCLUSÃO}

A dificuldade de comunicação e de absorção de todos aqueles que apresentam uma certa estranheza ou estrangeiridade é evidente nos textos analisados, tanto o conto de Murilo Rubião, tanto os episódios de Sodoma e Gomorra e do levita no relato de Juízes. Os anjos no primeiro texto, e o levita no segundo, por serem diferentes e externos a comunidades são hostilizados diretamente, são afrontados e ameaçada sua integridade física. Os dragões, a representação do desconhecido e do estranho, no conto de Rubião, sofrem, com o processo inicial de compreensão e conhecimento, uma pedagogia da assimilação, mas, por suas características excepcionais, são mantidos a distância pela comunidade amedrontada, imaginariamente coesa, até que, por fim, são eliminados para que a ordem seja restabelecida.

Em "Os dragões", a lei da hospitalidade é quebrada de forma subliminar: os estranhos são aparentemente aceitos, desde que cumpram, mesmo que obrigados, as inúmeras formas

\footnotetext{
17 Denominação genérica das diversas tribos habitantes da região de Canaã, a Terra Prometida, antes da chegada dos hebreus, após o Cativeiro no Egito. Seriam estes descendentes diretos do quarto filho de Cão, segundo filho de Noé. Os hebreus seriam descendentes de Sem, portanto, eram povos aparentados. Cf. BÍBLIA SAGRADA. Gn 10:6, p. 13.

${ }^{18}$ SODOM, SODOMITE, SODOMY. In: The International Standard Bible Encyclopedia. Disponível em: <http://unbound.biola.edu/>. Acesso em: 28 abr. 2008.
} 
pedagógicas que podem ser criadas para sujeitar as diferenças - aceitação de sua monstruosidade é condicionada. Incompreendidos, considerados inassimiláveis, como, aliás, foram considerados os judeus, não recebem os mesmos direitos e acessos. A comunidade se mantém fechada, talvez por medo, ou por não saber de onde vêm tais monstros, apenas comprovando a condição de limitação do homem. No conto de Rubião, portanto, não há saída possível para os dragões que agonizam ou fogem, tornando-se, cada vez mais raros e, portanto, menos assimiláveis. Estranhamente, a monstruosidade que poderia se esperar dos dragões migra, sorrateiramente, através da ficção, para o homem comum da cidade, como o professor que, instrumento da ordem, participa e colabora com a pedagogia do opressor.

\section{Abstract:}

Through a critical analysis of the Murilo Rubião's short-story "Os dragões" that will confront two biblical texts, we aim to show how a harmonious and closed community has difficulties accepting a stranger. In this essay, the breaking of the law of hospitality, considered a serious fault by the Jew community, will be examined along the text of "Job receives two angels at home" (Gen. 19:2-22) and "The Levite and his concubine" (Judg. 19), and will be analyzed according to the idea of the monster or the strange in a homogenous community.

Keywords: Murilo Rubião; hospitality; monster

Referências

BEREZIN, Rifka. Dicionário hebraico - português. São Paulo: Edusp, 1995.

BORGES, Jorge Luis. O livro dos seres imaginários. Trad. Heloisa Jahn. São Paulo: Companhia das Letras, 2007.

CHEVALIER, Jean; CHEERBRANT, Alain. Dicionário de símbolos: mitos, sonhos, costumes, gestos, formas, figuras, cores, números. Rio de Janeiro: Jose Olympio, 1997.

CIRLOT, Juan-Eduardo. Dicionário de símbolos. São Paulo: Moraes, 1984.

COHEN, Jeffrey Jerome. A cultura dos monstros: sete teses. In: SILVA, Tomaz Tadeu da (Org.). A pedagogia dos monstros: os prazeres e os perigos da confusão de fronteiras. Belo Horizonte: Autêntica, 2000. p. 23-60.

DONALD, James; SILVA, Tomaz Tadeu da. A cultura dos monstros: sete teses. In:

Pedagogia dos monstros: os prazeres e os perigos da confusão de fronteiras. Belo Horizonte: Autêntica, 2000. p. 89-139.

SOCIEDADE Bíblica do Brasil. Disponível em: http://www.sbb.org.br/. Acesso em: 7 maio 2008.

SHEDD, Russell. Bíblia Shedd. Editor responsável Russell P. Shedd; traduzida em português por João Ferreira de Almeida. 2. ed. rev. e atual. São Paulo: Vida Nova; Brasília: Sociedade Bíblica do Brasil, 1997. 
THE INTERNATIONAL STANDARD BIBLE ENCYCLOPEDIA. Disponível em: http://unbound.biola.edu/. Acesso em: 28 abr. 2008.

THE SEPTUAGINT ONLINE. Disponível em: <http://www.kalvesmaki.com/LXX/>. Acesso em: 7 maio 2008. 